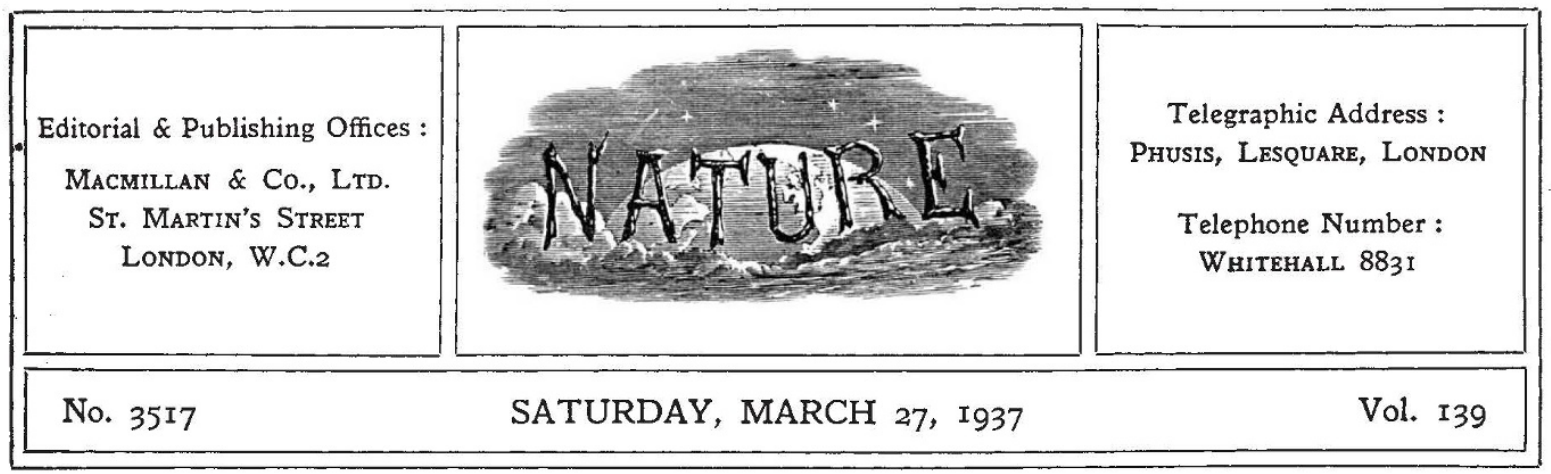

\title{
Science, Industry and Society
}

A LTHOUGH the recent annual report of the A Department of Scientific and Industrial Research, an article on which appears elsewhere in this issue, contains much evidence of the inoreasing readiness of industry in Great Britain to make use of scientific method and scientific knowledge, particularly in the progress of the Research Association movement, the Advisory Council does not regard the position of the Research Associations as a whole as satisfactory, and points out that adequate advantage is not yet being taken of the grant offered. This warning has since been reiterated from the industrial side in respect of the woollen industry by Mr. D. R. H. Wilkins, a leading Huddersfield worsted manufacturer, in proposing a vote of thanks to Dr. J. B. Speakman for a lecture to the Huddersfield Textile Society on "The Chemist and the Mill" on February 22. Mr. Wilkins referred strongly to the short-sightedness of those textile firms which justified reluctance to finance research by arguing either that they were doing well enough without it or that they are not doing well enough to afford it.

The woollen industry is one of the two specially mentioned by the Advisory Council as having failed to provide the initial subscription to their Research Associations to qualify for the substantial block grant offered by the Department. The reluctance of this industry to finance research on an adequate scale is the more surprising in view of the admirable work that is already being carried out by its Research Association at Torridon with limited resources, and of the important fundamental discoveries on the chemical and physical structure of wool which have been made at the neighbouring University of Leeds in recent years. Such reluctance, however, gives further point to the emphasis which the Advisory Council lays on organizing the conduct of research so as to promote contact with industry.

From the point of view of industry, the report urges, research is only a means to an end-the application of scientific knowledge to all the stages of production, and the development of new processes. The application and development of scientific ideas in industry depend upon a complete understanding of the way in which industry can make use of science and scientifio method, and this can only be achieved if the problem of cooperation is studied by the man of science as well as by the industrialist. The differences of experience, training and outlook between men of scientific education and many others engaged in productive industry are not always considered by those who are anxious to secure the potential benefits which science, wisely used, can bring to the community. The scientific worker has to meet the industrialist half way, and an important task of the Department of Scientific and Industrial Research is to assist the organization of such contact.

This question of co-operation, in one or other of its aspects, is probably the most important confronting industry and science to-day. It is not merely a matter of promoting contact between industry and science in such a way as to stimulate research in industries where it is at present comparatively neglected. The problem of promoting the application of science varies from industry to industry, partly by reason of the nature of the industry, partly by reason of its traditions and of the extent to which it has engaged the services of men of scientific training in its direction and its 
productive effort. The first step is, however, that of getting the industrialist to state his problems to the man of science, and to determine the order of priority, in terms of their economic importance, of the objectives of particular proposals for research.

The contribution which science can make to the solution of industrial problems depends on persevering effort on the part of industry and close co-operation between the industry and science. In this sphere, the staff of a research association can often make an invaluable contribution through their knowledge alike of the day-to-day problems of the industry and of science.

The statement of the problems concerned is important if the best method of attack is to be selected, because for industrial purposes to-day that may involve consideration not merely in terms of a particular science but also of a combination of sciences. Moreover, it may even involve consideration and attack from the point of view of several industries, if the fullest resources are to be utilized and the best results obtained. This, as the Advisory Council points out, is probably the most significant development in the industrial outlook in Great Britain in recent years.

The last five years have witnessed the fruition of the policy adopted by several large industrial undertakings of setting well-balanced teams of research workers including chemists, physicists, engineers, biologists or entomologists, and others to solve a particular problem or to develop a new product. To this method of attack are due the steady improvement in the efficiency of electric lamps, the position Great Britain has won in highdefinition television, the commercial development of the conversion of coal into oil by hydrogenation, the growth of the plastics industry, etc. Great Britain has never been lacking in men of genius whose inventive capacity can give birth to the ideas which bring about industrial advances. What is new in the country is the way in which industry has taken up these new ideas, and brought them to the stage of industrial development by team work in which all the departments comprising a great business have worked side by side in the practical attainment of an objective.

For economic reasons, as well as because of the high degree of specialization which the advance of knowledge has made inevitable in scientific fields, the future no longer lies with industries that are content to make advances at the call of the brilliant investigator. Co-operation, team work and an extensive organization are essential for success. Further, the exploration of the borderland of different sciences which is facilitated and stimulated by such team work has proved, as so often happens in the history of science, provo cative of new ideas and fundamental advances in knowledge. For this reason we need not fear that team work in research, if wisely organized and directed, need stifle individuality or cramp initiative or creative thought, as has been suggested in some quarters. Such dangers undoubtedly exist, but can easily be avoided by prudent management. Moreover, there is yet a third aspect of co-operation to which attention is directed, not merely by the report of the Department of Scientific and Industrial Research, but also by the recent appeal on behalf of the University of Oxford.

Among the examples of co-operative research to which the Advisory Council directs particular attention are the developments in building research and the formation of consultative groups in food investigation. The new Fire Testing Station which has been opened at Elstree represents the outcome of co-operation between the Building Research Station and the Fire Offices' Committee and in. directly the British Standards Institution, while similarly the Heating Laboratory which has been erected at the Building Research Station represents the outcome of substantial contributions from industry through the Institution of Heating and Ventilating Engineers. Again, the consultative groups which are being established by the Food Investigation Board are intended to assist in establishing a community of interest in the increase of scientific and technical knowledge through the whole range of industries concerned, whether production, transport, storage, marketing and retail distribution. The first of these groups has been established for the shipping industry and has proved highly successful, greatly facilitating dis. cussions between the staff of the Department and representatives of the shipping companies on the many problems connected with the carriage of foodstuffs overseas and also arrangements for fullscale trials of modifications in existing practice.

It would be easy, however, to multiply examples of the way in which co-ordination of the research activities of different industries is required in the attack on problems of common interest, or of the way in which only by some measures of co-operative research between different industries or Depart. ments of State can effective attack be made on problems of general national welfare and interest. What is, however, now emerging is the desirability 
of co-ordination of research effort in an even wider field if the best results are to be reaped from available resources.

This factor alone gives pertinence in this connexion to the recent appeal on behalf of the University of Oxford for $£ 500,000$ for each of two research funds. Advances in scientific knowledge make ever more onerous the task of schools of science, medicine and social studies in keeping abreast of the needs of an age of rapid material and technical development, and in making adequate provision for advanced studies and post-graduate research. Moreover, the very advances in natural sciences, with the concomitant calls for funds for erecting new laboratories or extending existing ones, equipping and staffing them, and for improving the facilities for research in the various science departments including the provision of research posts, only strengthen the claims for further funds for the better organization and extension of research in the humane subjects, particularly provision for the study of human society and allied subjects such as anthropology.

What is clear is that we have reached a stage when it is imperative to take stock of the nation's resources and facilities for research, both academic and industrial. To neglect or starve research is to invite national peril, but the danger of unbalanced development in certain fields while others remain scarcely explored is too great to be ignored. Some means of securing a better distribution of the national effort in research is indeed long overdue, and such distribution must take due account of all research activities and facilities, whether by the Departments of State, at the universities or within industry. To such a national stocktaking the Department of Seientific and Industrial Research might well make a decisive and indispensable contribution. Few organizations are in a better position to encourage the prosecution within industry itself of intensive research in the applied and physical sciences, with all the important reactions which such research continually has on the technique and outlook of the underlying sciences themselves. The relations between academic and industrial research in the physical sciences at the present time, the extent to which progress depends on team work, independent of whether the investigation is prosecuted within the university or within industry, the inspiration and assistance which academic and industrial research in these fields are continually bringing to one another, give fundamental research in the physical sciences special claims upon the support of industry, apart from the rapidity with which discoveries in this field are applied to industrial purposes. If the main burden of research in such fields were accepted by industrial resources, it should be possible to redistribute research facilities at the universities so as to endow much more liberally that research in the social sciences which is so urgently needed if we are to attain an understanding of the problems of society, its organization and adaptation to the forces playing upon it to-day, whether within industry or outside it. Without such understanding there is dire peril that the riches with which scientific knowledge could endow us even now may never be enjoyed.

Urgent as is this problem, it is not one to be solved in a few months or perhaps even a few years. A wide vision and a generous spirit are demanded of all who seek to co-ordinate research resources and endowments in any such way, and if we are to attain to wise direction of research it will come first through the bringing together of many authorities concerned, in much the same way as the Food Investigation Board has brought together the scattered interests concerned in its problems in the consultative groups to which we have referred. To restrain research in a narrow or partisan spirit is to endanger its finest quality and inspiration. Neither to natural science nor to the science of civilization can money be wisely grudged, and the distribution between the two can only be determined safely by minds inspired by the same vision of what may be achieved by skilled workers, governed only by the truth that makes them free, and in their turn the guardians of the intellectual integrity and freedom that have prompted famous donations to learning in the past.

No degree of co-operation, no excellence of team work will avail us if such direction does aught to impair the power of the university to promote and maintain true liberty of thought, which to-day is so seriously threatened in many quarters. It is only when, in that sense, the university not merely inspires the progress of civilization but also defends it, that we can expect free play for the creative thought upon which progress everywhere depends, alike in the study of the urgent practical problems of government and social life, human and international relations and in the fundamental problems continually brought before the scientific worker by industry. 